\title{
Unemployment and mortality: a small area analysis
}

\author{
JOHN RH CHARLTON*, RICHARD BAUER†, ANITA THAKHORE \\ SILVER\&, AND MARIA ARISTIDOU
}

From the Department of Community Medicine, United Medical and Dental Schools of Guy's \& St Thomas' Hospitals, St Thomas Campus, London SE1 7EH

SUMMARY It has been claimed that unemployment affects the health and thus the mortality of the unemployed, their families, and other members of their communities. This paper examines the relation between mortality and the unemployment experiences of small areas which vary in the extent to which their unemployment levels have changed in recent years. Quarterly numbers of unemployed, classified by age, sex, duration of unemployment, and unemployment office for 1977-81, have been aggregated to correspond to Family Practitioner Committee areas (FPCs), for which population and mortality data had been collected for a different study. There was little variation in long term $(>6$ months) unemployment trends prior to July 1980, but subsequently there were large variations between FPCs in the rate of increase in unemployment rates. Mortality data for suicide, ischaemic heart disease, cerebrovascular disease, and all causes were examined for the period 1975-83. When the mortality trends of FPCs with different unemployment experiences were compared, no statistically significant differences in trends were found, although areas with greater increases in unemployment appeared to have slightly worse mortality trends for suicide, ischaemic heart disease, cerebrovascular disease, and total mortality for men in the younger age groups. If changes in the level of unemployment do have an effect on changes in trends in mortality levels, this effect is not of sufficient magnitude to be statistically significant with the sample available, in spite of the fact that it included the whole of England and Wales.

While employment has been blamed for a considerable amount of physical ill health, ${ }^{1-3}$ more recently unemployment has been similarly implicated. It is obviously important to quantify such effects if they exist. While there appears to be a causal relation between unemployment and psychological health, ${ }^{4}$ the relation to physical health is not clear. Unemployed people tend to be less healthy, but it may be that their health contributes to the likelihood of their becoming unemployed rather than the other way around. Time series analyses have been used to "demonstrate" a relation between unemployment and mortality, ${ }^{4-9}$ but these studies have considerable limitations. ${ }^{10-12}$ Such analyses are frequently based on data spanning many years, with conclusions based on fitting complicated models with lag intervals determined post hoc which differ from analysis to analysis. It is difficult to draw clear conclusions, since

Present address:

- Department of Health and Social Security, Hanibal House, Elephant and Castle, London SEI

† Department of Medicine, University of Texas Health Science Center, San Antonio, 7703 Floyd Curl Drive, San Antonio, Texas, USA

‡ LOGICA Ltd, Computer Consultants, 64 Newman Street, London W1

$\$$ Institute of Education, London University there are many potential models and combinations of lag intervals. Long term changes in diagnostic practice, and possible changes in the relation between unemployment and health are also not considered. For example, current health service provision and welfare benefits may now prevent potential health consequences of unemployment.

We examine the hypothesis that unemployment affects the mortality of entire communities, using recent data relating to the entire populations of small areas of England and Wales. With such data we cannot investigate the effect on the health of the individuals who become unemployed. It is possible that within a community some individuals will benefit by being removed from the hazards of dangerous occupations, while others may suffer economic hardships and psychological stress which increase their risks of dying. What we observe is the net mortality change. We have taken advantage of a natural experiment by examining mortality data for a period which had three years of relatively stable unemployment rates followed by a rapid increase in unemployement in this second time period. If changes in unemployment are associated with changes in 
mortality, we would expect to find that mortality for certain causes such as suicide, ischaemic heart disease, and cerebrovascular disease would be less favourable for areas with large increases in unemployment rates than for areas with relatively small increases. Differences in mortality trends might only emerge some time after the date of onset of the increase in unemployment, but for the disease groups studied we expected the lag to be short. By examining data for recent years only, we hope that the effects of other confounding factors unrelated to unemployment will be small in comparison with the large changes that have occurred in levels of unemployment.

\section{Methods}

Numbers of unemployed persons, classified by unemployment office, age, sex, and duration (form EDS 82A), are published quarterly by the Department of Employment. Data for the period July 1977 to July 1981 were available on computer tape from the Greater London Council for 16 quarters for all the unemployment offices of England and Wales. There are some 900 offices open in any quarter. Using lists of office locations obtained from the Department of Employment and the Manpower Services Commission, these data were aggregated to the 98 Family Practitioner Committee areas (FPCs) for which mortality and population data for the period 1975-83 had been obtained for a separate study. Employment offices have boundaries of their own which do not coincide precisely with other boundaries, but this is not a serious problem when they are aggregated to these relatively large geographic units. The unemployment data for two specialist offices, London "Professional and Executive Recruitment" and "Hotel and Catering", were excluded from the aggregations since it was not clear how these should be treated.

The population and mortality data were supplied by the Office of Population Censuses and Surveys. Population data were mid-year estimates (final revised 1971-81 series) plus mid-year estimates for 1982 and 1983. Data were aggregated as necessary to conform to FPC geographic boundaries.

Previous research had shown that adverse psychological effects of unemployment were greatest in men in the middle age groups (who tended to have some work experience and family and financial commitments), and these increased with duration of unemployment, reaching a maximum at about six months. ${ }^{13}$ Thus we decided to focus our attention primarily on male unemployment of six months' duration and longer for the age group 25-44 years. This age group would also have the advantage that most would be economically active, hence population data would be valid as a denominator in calculating unemployment rates. We did, however, examine national trends for other age groups and durations of unemployment, and these were similar to the unemployment measure chosen, except that total unemployment started to rise some six months earlier than long term unemployment.

Figure 1 shows the national trend in numbers unemployed. Trends in long term (over six months' duration) unemployment among men aged $25-44$ were examined for each FPC. In each there was a sharp upturn in long term unemployment rates starting around July 1980 but relatively little change in unemployment in the period July 1977 to July 1980. There were three quarters for which data were not available (eg, as a result of industrial action): October 1977; July 1978; and January 1980. Thus trends for the two time periods were estimated using regression analysis, fitting two straight lines intersecting at July 1980 for each FPC (see fig 2), ie, if Y is the long term unemployment rate, the equation fitted was:

$$
\begin{array}{r}
Y=\mu+\alpha X_{1}+\beta X_{2} \\
\text { where } X_{1}=\quad \begin{array}{l}
t, \text { if } t \leqslant k \\
k \text { if } t>k
\end{array} \\
\text { and } X_{2}=\quad \begin{array}{l}
0, \text { if } t<k \\
t-k, \text { if } t \leqslant k
\end{array}
\end{array}
$$

and $\mathrm{k}$ corresponds to July 1980.

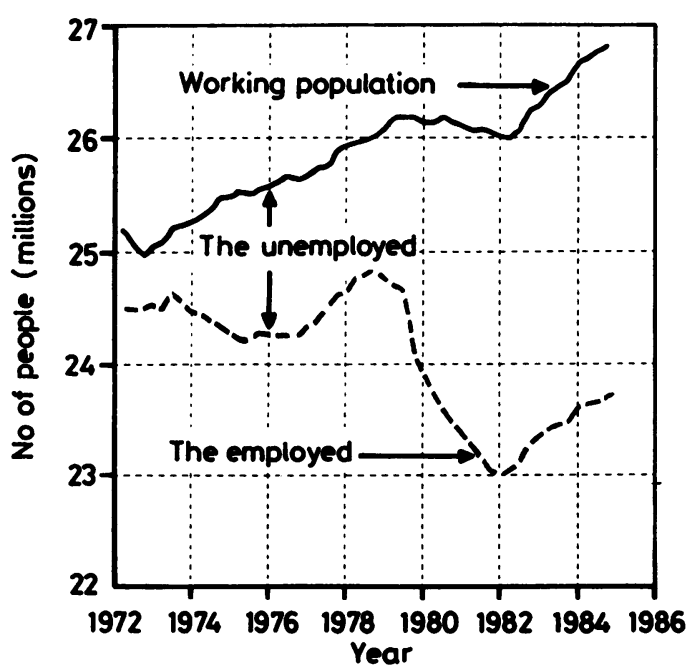

Fig 1 National trends in employment, 1972-85, showing trends in the size of the employed labour force, the working population, and hence the number of economically active people unemployed. Data are seasonally adjusted. Source: Employment Gazette, January 1986. 
Unemployment and mortality: a small area analysis

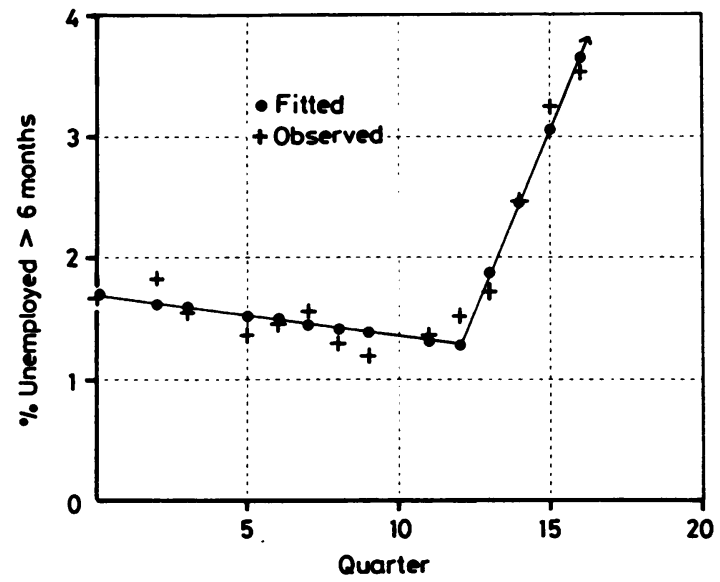

Fig 2 Observed and fitted long term (over 6 months) male unemployment rates in Cumbria, July 1977 (quarter 0) to July 1981 (quarter 16), ages 25-44. The point of inflection corresponds to July 1980.

Since these equations fitted the data extremely well, they were used to summarise the unemployment experience of the individual FPCs in terms of: long term unemployment at the beginning of the study period; rate of change in long term unemployment rate until July 1980; and afterwards. There was little variation in the rates of change in long term unemployment in the earlier time period. For graphical purposes, FPCs have been grouped together according to their long term unemployment experiences after July 1980 , and three groups were formed: slight increase (0-2\% increase per annum); moderate increase ( $2-4 \%$ increase per annum); and major increase (4-8\% increase per annum). This grouping was chosen to obtain roughly equal numbers of FPCs in each category but also to take account of the distribution of the data. Graphs were drawn showing the mortality trends of the populations falling in each of these categories.

We have studied causes of death where an association with unemployment is more plausible, and where the number of deaths is large enough to enable trends for specific age and sex groups to be examined: ischaemic heart disease; cerebrovascular disease; perinatal mortality; and suicide. Total mortality has also been included for comparative purposes. Mortality trends were examined for each age and sex group separately, since it was hypothesised that all groups might be adversely affected by unemployment, but perhaps to different extents, with men aged 25-44 the worst affected. The age groups considered were as follows: total mortality $0-14,15-24,25-44,45-54$, $55-64,65$ and over; perinatal mortality; suicide 15-24, 25-44, 45-64, 65 and over; cerebrovascular disease
25-54, 55-64, 65 and over; ischaemic heart disease $25-44,45-54,55-64$ and over. For age and sex groups where the number of deaths was too small to justify trend analyses, age groups were widened. The effect on mortality for each of these disease categories was hypothesised to be greatest in men aged 25-44.

Regression analyses of mortality trends were undertaken using the actual rate of change in unemployment in each FPC. Trends in age-specific mortality rates over the period 1980-83 were examined for each sex by means of logistic regression, using the GLIM regression package ${ }^{14}$ to determine whether the mortality trends for FPCs with different unemployment experiences were significantly nonparallel. In these analyses the data were analysed in two ways: (1) using a model which included only YEAR (a factor) and EXPERIENCE (rate of change in long term unemployment after July 1980); and (2) adjusted for the following factors: level of unemployment at the beginning of the study period; and a constant term for each FPC, representing local conditions. The trends were significantly non-parallel if the YEAR.EXPERIENCE terms were statistically significant. The existence of other two-way interactions was also tested.

\section{Results}

During the period studied national unemployment rates were at first relatively constant, but since 1979 they have continued to rise (fig 1), with long term (over six months) unemployment rising sharply from July 1980 onwards. There were considerable variations between FPCs in the level of unemployment in July 1977. Regression equations fitted to the data on long term male unemployment for each FPC (comprising two straight lines intersecting at July 1980 , as described under Methods) fitted the data extremely well (see, for example, fig 2 and table). The FPCs for

Summary of variations among the 98 Family Practitioner Committee areas of England and Wales in regression estimates for long term ( $>6$ months) unemployment rates, men aged 25-44 years

\begin{tabular}{llllll}
\hline Regression estimate & Mean & $\begin{array}{l}\text { Standard } \\
\text { deviation } \\
(\%)\end{array}$ & \multicolumn{2}{l}{ Range } & \\
& $(\%)$ & $(\%)$ & \\
\hline $\begin{array}{l}\text { Unemployment July 1977 } \\
\begin{array}{l}\text { Change per year, July 1977- } \\
\text { July 1980 }\end{array}\end{array}$ & 2.4 & 1.5 & $0.5-$ & 10.8 \\
$\begin{array}{l}\text { Change per year, July 1980- } \\
\text { July 1981 }\end{array}$ & 2.8 & 0.1 & & $-0.8-$ & 0.4 \\
$\begin{array}{l}\text { Percentage of variance } \\
\text { explained by regression } \\
\text { model (see Methods) }\end{array}$ & 94.7 & 4.0 & & $0.8-$ & 8.0 \\
\hline
\end{tabular}



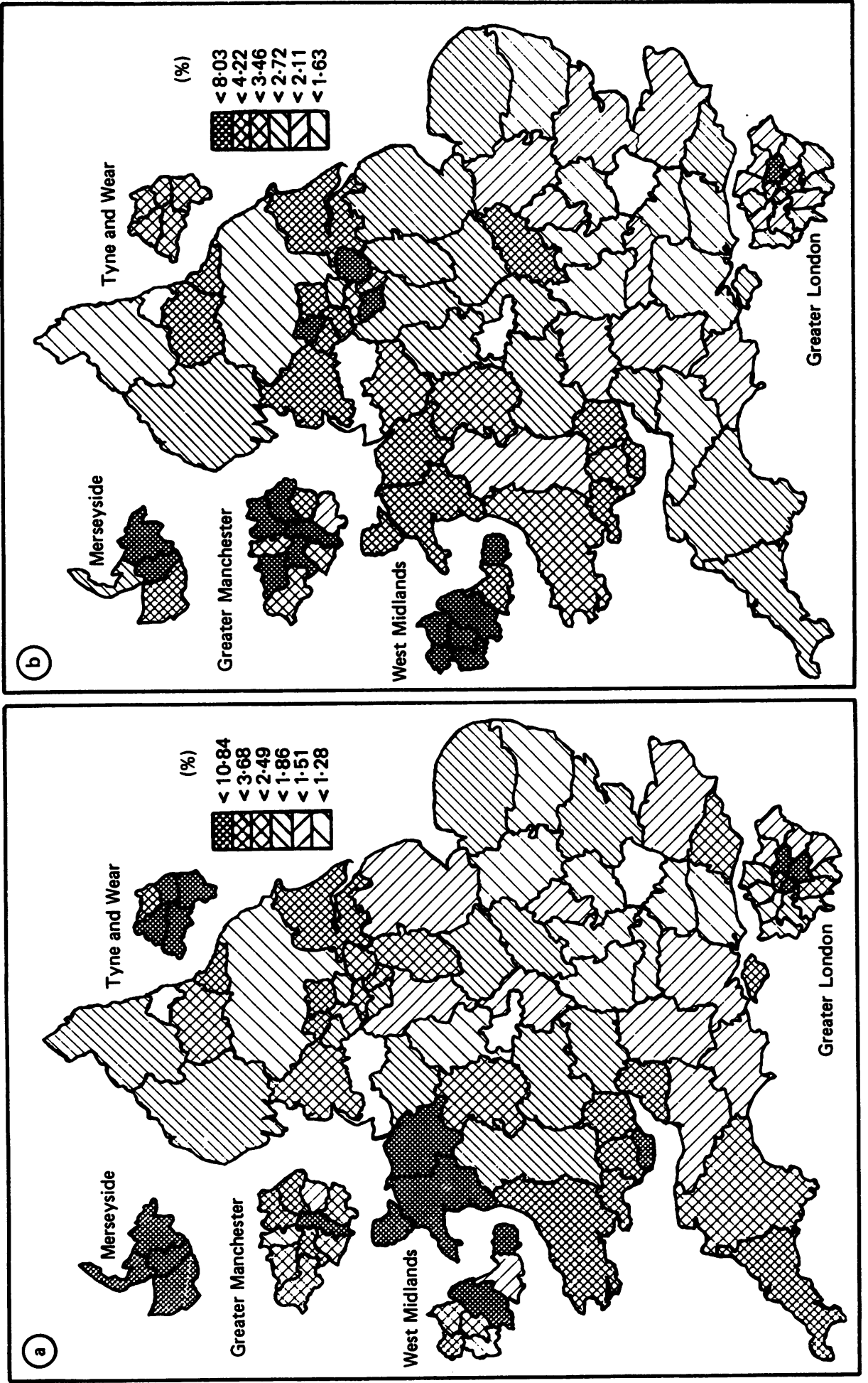
which the fit was less good were ones that had greater seasonal variations (eg, the Isle of Wight). There were relatively small variations in rates of change in long term employment rates between July 1977 and July 1980 but major variations after July 1980 . The areas with the greatest increases in unemployment rates in the second time period tended to be those with the highest long term unemployment rates in July 1977 (fig 3).

Graphs were drawn showing the mortality trends for different age groups for men and women separately. Figures 4 to 7 show mortality trends for

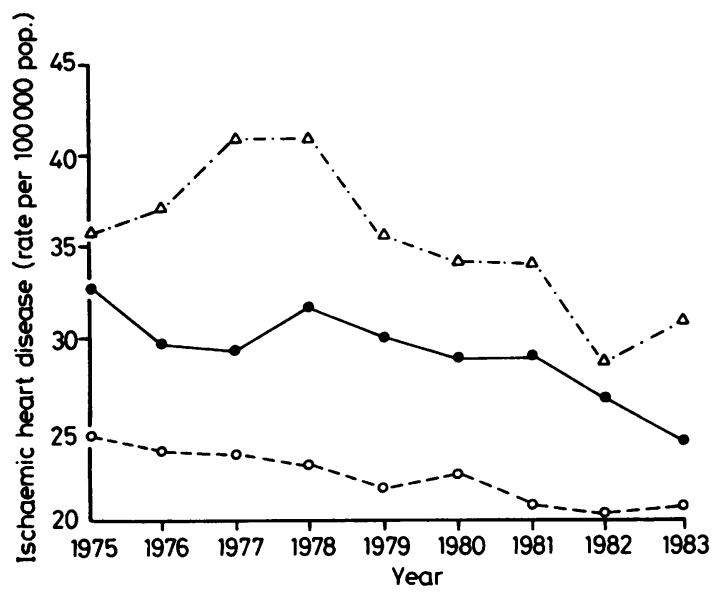

Fig 4 Male IHD mortality trends for FPCs with minor (O--O: 0-2\%), moderate (O-O: $2-4 \%$ ), and major $(\Delta \cdot-\Delta: 4-8 \%)$ increases in long term (over 6 months) unemployment, July 1980-July 1981, ages 25-44.

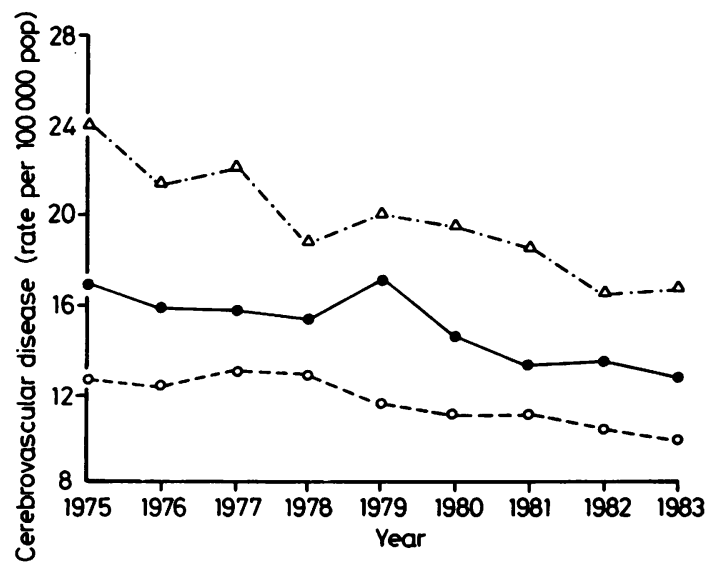

Fig 5 Male CVD mortality trends for FPCs with minor (O- $-0: 0-2 \%)$, moderate (O- $: 2-4 \%)$, and major ( $\triangle \cdot-\Delta: 4-8 \%$ ) increases in long term (over 6 months) unemployment, July 1980-July 1981, ages 25-54.

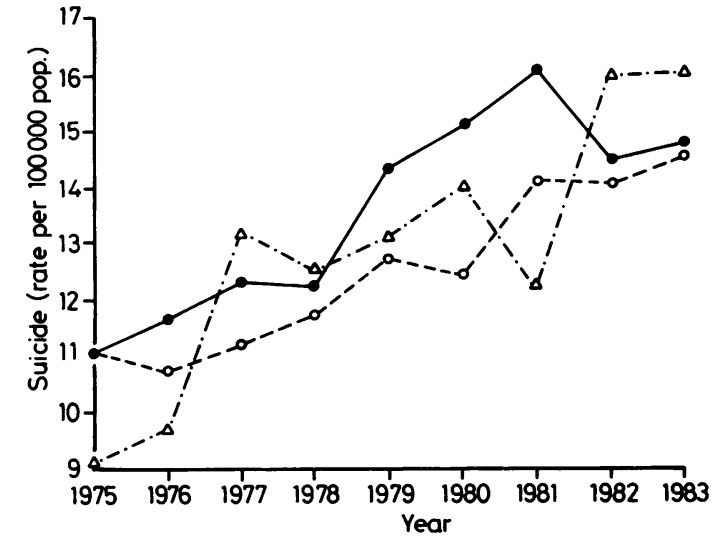

Fig 6 Male suicide mortality trends for FPCs with minor (O--O: 0-2\%), moderate (O-O: 2-4\%), and major $(\triangle \cdot-\triangle: 4-8 \%)$ increases in long term (over 6 months) unemployment, July 1980-July 1981, ages 25-44.

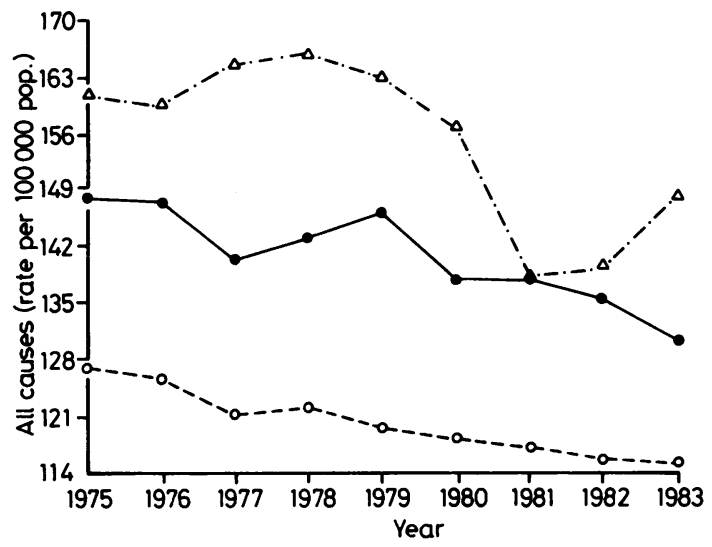

Fig 7 Male total mortality trends for FPCs with minor (O--O: 0-2\%), moderate (0-0: 2-4\%), and major $(\Delta \cdot-\Delta): 4-8 \%$ ) increases in longterm (over 6 months) unemployment, July 1980-July 1981, ages 25-44.

men aged 25-44 (25-54 for cerebrovascular disease) for the FPCs which experienced "slight" (0-2\%), "moderate" (2-4\%), and "major" (over 4\%) increases per year in long term unemployment after July 1980. Ischaemic heart disease (IHD) and cerebrovascular disease (CVD) mortality rates declined significantly ( $p$ $<0.01$ ) in the study period, FPCs which had experienced greater increase in long term unemployment tending to have higher overall mortality $(p<0.01)$. In 1983, the IHD and CVD mortality rates of FPCs which had had the greatest increases in unemployment levels seemed to rise, in contrast to the decline in rates for FPCs where there was a smaller increase in unemployment, but these 
rises were not statistically significant. FPCs with the smallest increases in unemployment had the lowest suicide mortality rates for the entire study period $(p<$ 0.05 ). Suicide mortality increased for all three groups, and this increase is statistically significant $(\mathrm{p}<0.01)$ but is merely a continuation of the pre- 1980 trend. The group of areas that experienced the largest increases in unemployment rates had relatively greater increases in suicide, changing from having the lowest suicide rates to having the highest, but these differences in trends are not statistically significant. All-cause mortality also fell during the study period $(p<0.01)$ and was also higher overall in the FPCs that experienced greater unemployment rises $(p<0.01)$. In the areas with the greatest increases in long term unemployment there was a sharp fall in mortality between 1980 and $1981\left(\mathrm{X}_{4}^{2}=15, \mathrm{p}<0.01\right)$ with mortality for 1982 and 1983 returning to levels in line with the previous trend.

Ischaemic heart disease and cerebrovascular disease mortality rates for men and women in the other age groups studied were significantly higher overall during 1975-83 in those FPCs that experienced greater rises in long term male unemployment. In none of these comparisons, however, are the trends significantly different for FPCs with different rates of change in male long term unemployment after July 1980.

Figure 8 shows trends in female suicide for ages 25-64, and figure 9 shows trends in perinatal mortality. There is much less suicide mortality among women than among men, which is why such a broad age group was chosen. Female suicide has declined in all three groups. Perinatal mortality was higher among FPCs that experienced greater rises in unemployment, but the trends for FPCs with different unemployment experiences were parallel. For none of the age-sex-

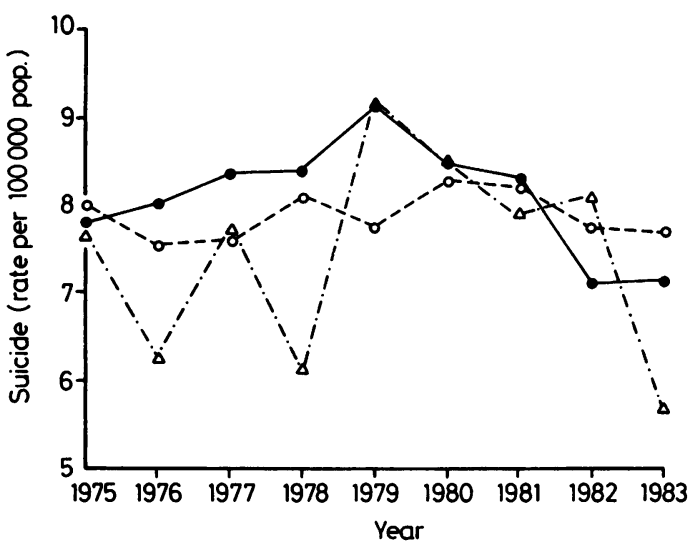

Fig 8 Female suicide mortality trends for FPCs with minor (O--O: 0-2\%), moderate (O-O: 2-4\%), and major $(\triangle \cdot-\triangle: 4-8 \%)$ increases in long term (over 6 months) unemployment, July 1980-July 1981, ages 25-64.

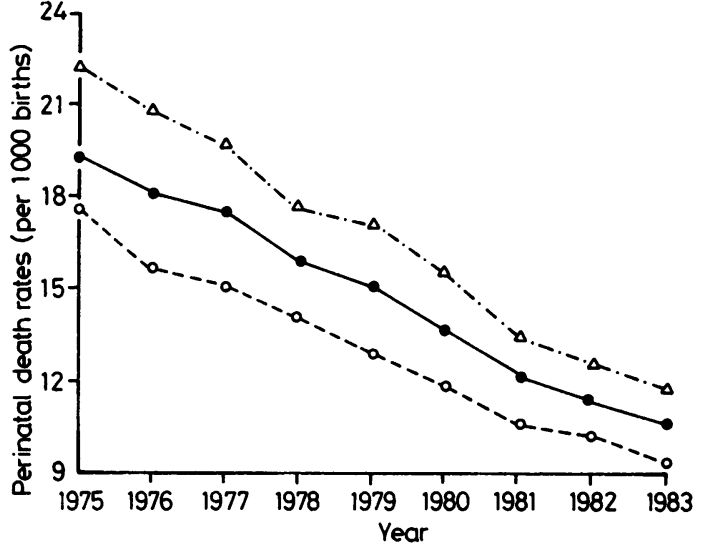

Fig 9 Perinatal mortality trends for FPCs with minor (O--O: 0-2\%), moderate (0-0: 2-4\%), and major $(\Delta \cdot-\Delta: 4-8 \%)$ increases in long term (over 6 months) unemployment, July 1980-July 1981.

mortality groups studied was there statistically significant evidence of a link between a rise in long term unemployment and a subsequent or simultaneous increase in mortality.

\section{Discussion}

Our results do not confirm Brenner's predictions ${ }^{5}$ that a rise in unemployment leads to a rise in mortality. We have failed to find any statistically significant association between changes in unemployment of communities and changes in their mortality levels, in spite of having large samples and wide variations in the rate of change in unemployment. Clearly, some individuals may commit suicide or die of other causes as a result of their unemployment or the unemployment of other family members. This effect may have been too small to detect in this analysis, or these deaths may be counterbalanced by a decrease in work-related deaths. Using the same source of data as Brenner, Eyer concluded that full employment leads to an increase in mortality rates. ${ }^{9}$ Our results suggest that a large increase in long term unemployment in England and Wales is, under today's conditions, unlikely to be followed by a rise in mortality rates. It could be argued that three and a half years of follow-up are insufficient to detect any adverse effects of unemployment on mortality. Also, different patterns of unemployment in individual areas may have had different impacts over a considerable period of time, and thus the study period might be considered to have been too short. We cannot reject these arguments with the data to hand, but our results do not fit the model proposed by Brenner for the effects of unemployment on suicide, 
ischaemic heart disease, cerebrovascular disease, perinatal deaths or all-cause mortality, which involved short lag periods.

In general, the areas with greater increases in unemployment were also the areas with highest mortality. These areas tended to have higher proportions of unskilled workers and already had high unemployment. Unemployment is likely to affect the least skilled first, and a tendency to become unemployed may thus be an alternative measure of social disadvantage. Moser ${ }^{15}$ found that men who on census night (1971) were seeking work, and their wives, tended to have higher than average subsequent mortality from a number of causes. This excess mortality persists when high and low mortality regions are examined separately. ${ }^{16}$ These findings, however, do not rule out the possibility of a selection effect. Narendranthan et al, ${ }^{17}$ in a recent analysis of data from the Manpower Services Commission National Training Survey, which provides retrospective longitudinal data on spells of sickness, unemployment and employment, concluded that sickness and unemployment were concentrated in lower socioeconomic groups. Unskilled workers were about five times more likely to have had a long spell of unemployment and ten times more likely to have had a long spell of sickness during the previous ten years than were professionals. Further, each time an individual had a long spell of unemployment, it raised the probability of a further spell, with the same applying to sickness. There was, however, "little evidence in these data that unemployment spells raise the probability of future sickness."

We do not conclude that unemployment is without harmful effects for individuals. It is clear that unemployment can have a devastating effect on the income of individuals, family, and community, and it is indisputably a matter for public concern. This study is restricted to examining the mortality of communities. There is strong evidence that unemployment can have unfortunate psychological consequences for the majority of individuals, ${ }^{4}$ and it is possible that through this link long term unemployment may eventually have physical consequences for some. However, if changes in unemployment do have an effect on the mortality of communities it is not of sufficient magnitude to be statistically significant in the time scale examined, in spite of the fact that the sample comprised the whole of England and Wales.
We are grateful for the encouragement and advice of Professor WW Holland and suggestions made by Professor L Oppit. We are also grateful for Professor S Kasl's comments on the manuscript. The study was funded in part by the Department of Health and Social Security and was initiated while one of us (RB) was a Milbank Fund Fellow.

\section{References}

${ }^{1}$ Department of Employment, Safety and Health at Work: Report of the Committee 1970-72 (Chairman: Lord Robens), HMSO, cmnd 5034, 1972.

2 Alderson M, ed. The prevention of cancer. London; Edward Arnold: 1982.

${ }^{3}$ Eyer J. Prosperity as a cause of death, International Journal of Health Services Research, vol 7 no 1, 1977: 125-50.

4 Warr P. Job loss, unemployment and psychological wellbeing, in: Van de Vliert E \& Allen V (Eds) Role transitions, 1983, New York: Plenum Press.

5 Brenner MH. Health costs and benefits of economic policy. Int J Health Services, 1977; 7: 581-623.

6 Brenner MH. Mortality and the national economy: a review of the experience of England and Wales, 1936-76, Lancet 1979; ii: 568-73.

${ }^{7}$ Brenner MH, Mooney A. Unemployment and health in the context of economic change. Soc Sci Med 1983; 17: 1125-38.

${ }^{8}$ Bunn AR. Ischaemic heart disease mortality and the business cycle in Australia. Am J Pub Health, 1979; 69: 772-81.

${ }^{9}$ Eyer J. Does unemployment cause the death rate to peak in each business cycle? Int J Health Serv, 1977, 7; 625-62.

${ }^{10}$ Gravelle HSE, Hutchinson G, Stern J. Mortality and unemployment: a critique of Brenner's time series analysis. Lancet 1981; ii: 675-81.

$11 \mathrm{Kasl}$ SV. Mortality and the business cycle: Some questions about research strategies when utilising macro-social and ecological data. Am J Pub Health 1979; 69: 784-8.

$12 \mathrm{Kasl} \mathrm{SV}$. Strategies of research on economic instability and health. Psychological Medicine 1982; 12: 637-49.

13 Warr P, Jackson P. Men without jobs: some correlates of age and length of unemployment. J Occup Psychol 1984; 57: 77-85.

14 Baker RJ. Nelder JA. The GLIM system release 3 Oxford; Numerical Algorithms Group, 1978.

15 Moser KA, Fox AJ, Jones DR. Unemployment and mortality in the OPCS longitudinal study. Lancet, 1984, ii: $1324-8$.

${ }^{16}$ Moser KA, Fox AJ, Jones DR, Goldbladt PO. Unemployment and mortality: further evidence from the OPCS longitudinal study 1971-1981. Lancet 1986, i: 365-6.

17 Narendranthan W, Nickell S, Metcalf D. An investigation into the incidence and dynamic structure of sickness and unemployment in Britain, 1965-76. $J R$ Statist Soc A 1985; 148 part 3: 254-67. 